\title{
Coxalgia crónica: necrosis avascular de la cabeza femoral
}

\author{
M. A. Castellano del Castillo, A. González Álvarez*, M. A. Blanco Ramos** \\ Médico Especialista en Rehabilitación. Servicio de Rehabilitación. Fundación Hospital Verín. Ourense. \\ * Médico Especialista en M edicina Interna. Coordinador del Centro de Salud Novoa Santos. Ourense. \\ **M édico Especialista en Medicina Familiar y Comunitaria. Técnico de Salud de la Unidad de Inves - \\ tigación del Complejo Hospitalario de Ourense. Ourense.
}

\section{Chronic hip pain: femur head necrosis}

\section{RESUMEN}

La necrosis avascular ósea es una entidad pato lógica poco frecuente que puede aparecer de forma idiopática o bien ser secundaria a diversas patolo gías. Puede encontrarse a distintos niveles, siendo los más frecuentes en el adulto la cabeza femoral y el escafoides carpiano.

En el caso de localizarse en la cadera da lugar a una coxalgia, cuadro frecuentemente estudiado en los centros de Atención Primaria, por lo que es тиy importante su diagnóstico diferencial y precoz, so bre todo en caso de existir factores de riesgo.

Presentamos un caso clínico de necrosis avascu lar de la cabeza femoral y hacemos una revisión de lo expuesto en la bibliografía actual al respecto.

Palabras clave: Cadera. Dolor. Necrosis avas cular.

\begin{abstract}
Avascular bone necrosis is a very rare patholo gical entity that can appears in an primary way or a secondary one due to diverse factors. It can be found in a few levels, especially in the femoral he ad and the carpal navicular bone in the adult patient.

If the lession is located in the femoral head le ads to a hip pain, a very frequent clinical manifes tation studied in Primary Health Care centers, so it is very important its early and differential diagno sis, above all, in the case that exist risk factors.

We present a clinical case of avascular necrosis of the femoral head and perform a current biblio graphic revision on the matter.
\end{abstract}

Key words: Hip. Pain. Femur head necrosis.

\section{INTRODUCCIÓN}

Una de las causas que más consultas suponen a nivel de Atención Primaria es la patología de aparato locomotor. El aumento de la esperanza de vida da lugar al seguimiento y tratamiento de multitud de cuadros articulares degenerativos. Además, la cada vez más extendida práctica deportiva lleva al facultativo a enfrentarse a diario con una gran variedad de alteraciones musculoesqueléticas.

Una de las presentaciones sintomáticas más frecuentes es la coxalgia. En principio, y especialmente en el anciano, ésta se debe a una degeneración artrósica de la articulación coxofemoral. Pero también puede ser debida a un amplio grupo de procesos que deben ser conocidos y descartados en la valoración del paciente. La necrosis avascular de la cabeza femoral, aunque poco frecuente, es uno de ellos. La gravedad de las secuelas que puede producir hace necesario su estudio, sobre todo en sujetos con factores de riesgo asociados.

\section{CASO CLÍNICO}

Mujer de 51 años de edad con cuadro de importante obesidad como único antecedente patológico de interés. Presenta coxalgia bilateral, siendo más 
intensa del lado derecho, de un año y medio de evolución. No refiere antecedente traumático ni sobreesfuerzo. El dolor comenzó de forma insidiosa con características mecánicas (aumentando con el movimiento y cediendo con el reposo), para más tarde hacerse más continuo e incorporar también un componente nocturno. Se acompañaba de limitación articular y exacerbación dolorosa con la abducción y las rotaciones activas y pasivas. La deambulación se veía comprometida, especialmente en la fase de apoyo total, y se realizaba un patrón de marcha antiálgico. La paciente refería simultáneamente gonalgia bilateral. El cuadro doloroso no cedió con tratamiento antinflamatorio vía oral y reposo. Se solicitó estudio de radiología simple de pelvis con ambas caderas y rodillas, que mostró una irregularidad y deformidad de la cabeza femoral derecha, con esclerosis y geodas subcondrales, junto con una relativa conservación del espacio articular, compatible todo ello con osteonecrosis avascular de la cabeza femoral derecha (Fig. 1). Así mismo se observaban imágenes de cambios de-

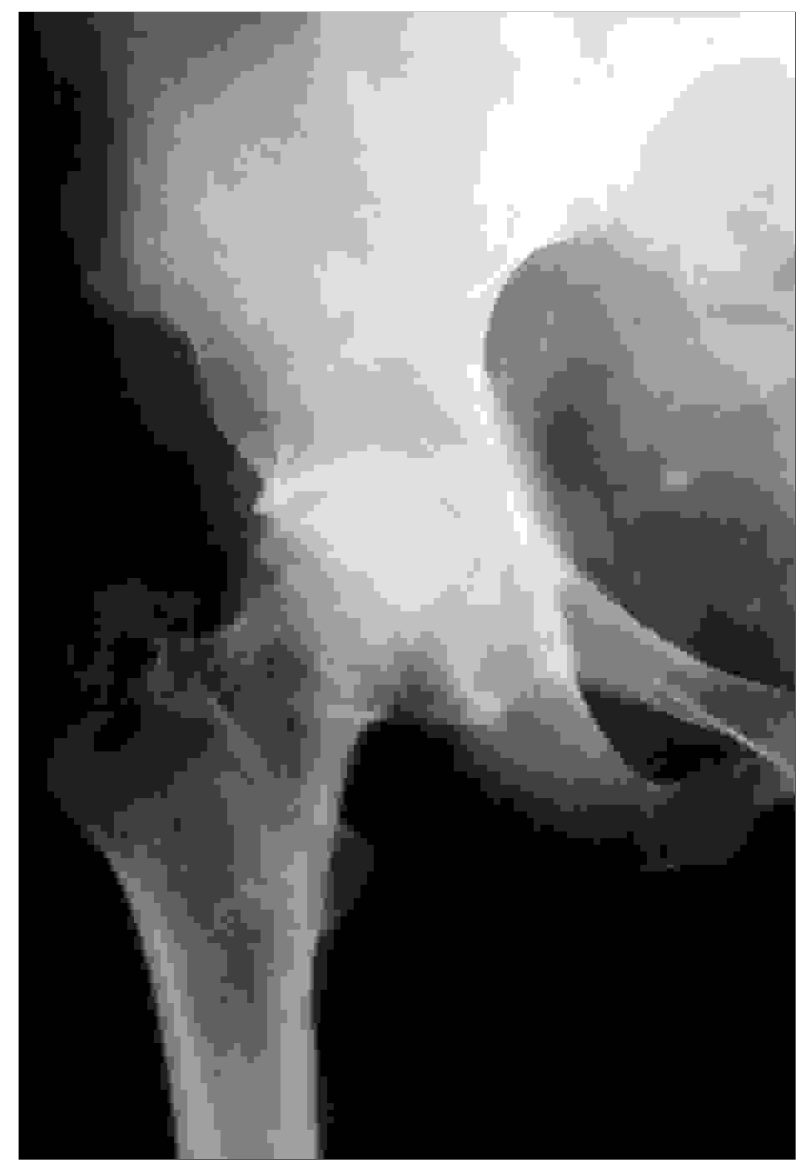

Figura 1

Radiografía simple de cadera derecha. Proyección anteroposterior. Irregularidad del contorno de la cabeza femoral junto con esclerosis y estrechamiento del espacio articular. generativos artrósicos en la cadera izquierda y en ambas rodillas.

La paciente fue remitida al traumatólogo de área, el cual decidió completar el estudio mediante una Tomografía Computerizada (TC). Se confirmo la sospecha clínica al verificarse dicha deformidad de la cabeza femoral derecha con aplanamiento e irregularidad de su cortical a nivel anterosuperior, existiendo geodas y esclerosis subcondral, así como una banda radiolucente subcondral con interrupción de la cortical (Fig. 2).

Con el diagnóstico confirmado de osteonecrosis de la cabeza femoral derecha se optó por el tratamiento quirúrgico mediante una artroplastia total de cadera. Tras la intervención la paciente fue remitida al Médico Especialista en Rehabilitación para su valoración, presentando la siguiente exploración física: cicatriz quirúrgica no adherida ni dolorosa. Dolor difuso a la palpación de la cadera. Balance articular: $80^{\circ}$ de flexión, $-10^{\circ}$ extensión, $30^{\circ}$ abducción, $25^{\circ}$ adducción. Balance muscular 4/5 global. No déficits sensitivos distales. Pulsos periféricos presentes. Buen relleno vascular distal. Deambulación con dos bastones ingleses. Se pautó tratamiento rehabilitador mediante 28 sesiones de fisioterapia y electroterapia, lográndose una buena evolución clínica. Al alta en el Servicio de Rehabilitación la paciente no refería coxalgia. No dolor a la palpación de la cadera. Cicatriz quirúrgica normal. Balance articular: $100^{\circ}$ flexión, $10^{\circ}$ extensión, $40^{\circ}$ abducción y $45^{\circ}$ de adducción. Balance muscular 5/5. Deambulación independiente sin ayudas técnicas.

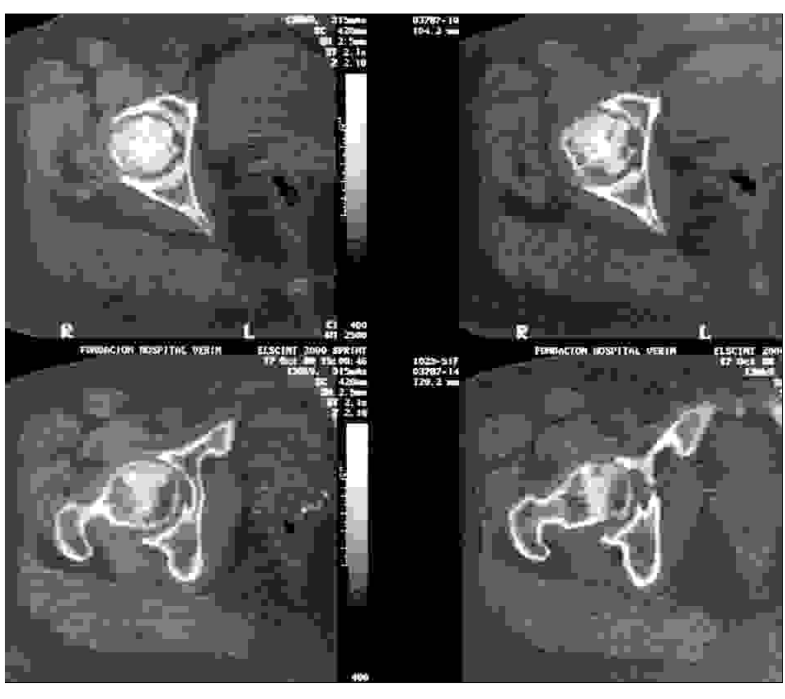

Figura 2

Corte axial de tomografía computerizada de cadera derecha. Ventana ósea. Se pueden apreciar imágenes de esclerosis subcondral, así cómo una banda radiolucente subcondral con interrupción de la cortical. 


\section{DISCUSIÓN}

Distintas patologías pueden dar lugar a la aparición de un cuadro de necrosis avascular ósea (NAO) en el adulto. Podemos establecer dos grandes grupos en función de la etiopatogenia del proceso:

- Las NAO postraumáticas, en las que se produce una interrupción aguda e intensa de la vascularización.

- Las NAO no traumáticas u osteonecrosis idiopáticas, debidas a distintos factores que originarían una coagulación intravascular local (Tabla I).

La NAO de la cabeza femoral es la responsable del 3\% de las coxopatías del adulto, con una incidencia de un caso nuevo por cada millón de habitantes al año. Aparece más frecuentemente en el varón y predomina en el grupo de edad comprendido entre los 30 y los 60 años. En el $60 \%$ de los casos es bilateral ${ }^{1}$.

La sintomatología predominante es la coxalgia, que puede debutar de forma brusca e intensa o bien mostrar una evolución progresiva con características mecánicas. Se acompaña de una contractura muscular periarticular asociada, en la mayoría de los casos, y una limitación de la movilidad articular activa y pasiva, especialmente marcada en los movimientos de abducción y rotación. Todo ello puede dar lugar a una importante discapacidad ${ }^{2}$.

El diagnóstico clínico se confirma mediante el estudio por la imagen. La radiología simple es una técnica que sirve para el diagnóstico en etapas tardías. Ante la sospecha de NAO se recomienda utilizar la RM y la gammagrafía ósea ${ }^{3-5}$. Esta última es poco específica, pero sensible para localizar las zo-

\begin{tabular}{|l|}
\hline FACTORES CAUSALES DE NECROSIS AVASCULAR ÓSEA \\
\hline Alcoholismo \\
Hemoglobinopatías \\
Hiperlipemias \\
Hiperuricemia \\
Anemia drepanocítica \\
Osteodistrofia renal \\
Obesidad \\
Uso sistémico de esteroides \\
Shock séptico \\
Enfermedad inflamatoria intestinal \\
Lupus eritematoso sistémico \\
Neoplasias \\
Embarazo \\
\hline
\end{tabular}

nas afectadas. El mejor método no invasivo es la $\mathrm{RM}$, donde se ven imágenes homogéneas o no, con disminución de la señal en la región subarticular. Si persiste la sospecha de NAO y la RM es normal se debe hacer una gammagrafía ósea, que si también resultase negativa, se aconseja repetir cada 2-4 meses. Una vez establecida la lesión (como en el caso que presentamos) la TC se caracteriza por su efectividad en la identificación de fracturas y en el estadiaje del proceso $^{5,6}$.

La clasificación más preponderante sobre la necrosis avascular de la cabeza femoral es la desarrollada en función de los cambios radiográficos por Ficat y Arlet $^{7}$ (Tabla II).

Tabla ll

\begin{tabular}{|c|c|c|c|c|}
\hline \multicolumn{5}{|c|}{ ESTADIOS DE LA NECROSIS AVASCULAR DE LA CABEZA FEMORAL DE FICAT Y ARLET } \\
\hline Estadio & Síntomas & Radiología & Gammagrafía & Patología \\
\hline 0 & Ninguno & Normal & ¿Captación disminuida? & \\
\hline 1 & Ninguno o leves & Normal & $\begin{array}{l}\text { Zona fría en } \\
\text { cabeza femoral }\end{array}$ & $\begin{array}{l}\text { Infarto de la zona de la } \\
\text { cabeza que soporta } \\
\text { el peso }\end{array}$ \\
\hline 2 & Leves & $\begin{array}{l}\text { Cambios de densidad } \\
\text { en la cabeza femoral }\end{array}$ & $\begin{array}{l}\text { Aumento de la } \\
\text { captación }\end{array}$ & $\begin{array}{l}\text { Reparación espontánea } \\
\text { de la zona infartada }\end{array}$ \\
\hline $2 \mathrm{~A}$ & & $\begin{array}{l}\text { Esclerosis o quistes, llínea } \\
\text { articular normal, contorno } \\
\text { cabeza femoral normal }\end{array}$ & & \\
\hline $2 B$ & & Aplanamiento (signo de la semiluna) & & \\
\hline 3 & Leves a moderados & Pérdida de la esfericidad, colapso & Aumento de la captación & $\begin{array}{l}\text { Fractura subcondral, } \\
\text { colapso y fragmentación } \\
\text { del segmento necrótico }\end{array}$ \\
\hline 4 & Moderados a graves & $\begin{array}{l}\text { Estrechamiento del espacio articular, } \\
\text { cambios acetabulares }\end{array}$ & Aumento de la captación & Cambios osteoartríticos \\
\hline
\end{tabular}


El tratamiento a aplicar está en función del estadio de Ficat en que se encuentre la NAO. En los estadios iniciales I y II la aplicación de magnetoterapia a baja intensidad (0-40 Gauss) mediante campos electromagnéticos pulsados, ha demostrado su efectividad ${ }^{8,9}$. También se ha utilizado la descompresión quirúrgica del núcleo en estos estadios. En los estadios avanzados III y IV el tratamiento de elección, a menos que existan contraindicaciones formales, es la realización de una artroplastia total de cadera, que ha mostrado unos buenos resultados a largo plazo en estos pacientes ${ }^{10,11}$. El tratamiento rehabilitador, pautado por el Médico Especialista en Rehabilitación correspondiente, ha demostrado lograr una importante mejoría funcional tras la realización de la artroplastia $^{12,13}$.

\section{CORRESPONDENCIA:}

M.A. Castellano del Castillo

Servicio de Rehabilitación

Fundación Hospital Verín.

Ctra. De Laza s/n

32600 Verín. Orense.

\section{Bibliografía}

1. López-Durán L. Necrosis óseas avasculares. En: LópezDuran L. Traumatología y Ortopedia. $2^{\mathrm{a}}$ ed. Madrid: Luzán, 1995; 5: 115-7.

2. Coombs RR, Thomas RW. Avascular necrosis of the hip. $\mathrm{Br}$ J Hosp Med 1994; 51(6): 275-80.

3. Mitchell MD, Kundel HL, Steimberg ME, Kressel HY, Alavi A, Axel L. Avascular necrosis of the hip: comparison of MR, Ct and scintigraphy. AJR Am J Roentgenol 1996; 147 (1): 67-71.

4. Markisz JA, Knowles RJ, Altchek DW, Schneider R, Whalen JP, Cahill PT. Segmental patterns of avascular necrosis of the femoral heads: early detection with MR imaging. Radiology 1987; 162 (3): 717-20.

5. Mitchell DG, Kressel HY, Arger PH, Dalinka M, Spritzer CE, Steimberg ME. Avascular necrosis of the femoral head: morphologic assesment by MR imaging, with CT correlation. Radiology 1986; 161 (3): 739-42.

6. Manero FJ, Castellano MA, Manero I. Radiología ósea. Medicina Integral 1997; 30 (5): 217-9.

7. Dutkowsky JP. Trastornos no traumáticos diversos. En: Crenshaw AH. Campbell. Cirugía Ortopédica. $8^{\mathrm{a}}$ ed. Buenos Aires: Panamericana, 1994; 1922-4.
8. Aaron RK, Lennox DW, Bunce GE, Ebert T. The conservative treatment of osteonecrosis of the femoral head: a comparison of core compresion and pulsing electromagnetic fields. Clin Orthop 1989; 249 (1): 209-18.

9. Rioja Toro J. Magnetoterapia. En: Rioja Toro J. Electroterapia y electrodiagnóstico. $2^{\mathrm{a}}$ ed. Valladolid: Universidad de Valladolid 1996; 299-309.

10. Xenakis TA, Beris AE, Malizos KK, Koukoubis T, Gelalis J, Soucacos PN. Total hip arthroplasty for avascular necrosis and degenerative osteoarthritis of the hip. Clin Orthop 1997; 341: 62-8.

11. Garino JP, Steimberg ME. Total hip arthroplasty in patients with avascular necrosis of the femoral head: a 2 to 10 year follow up. Clin Orthop 1997; 334: 108-5.

12. Walker WC, Keyser-Marcus LA, Cifu DX, Chaudhri M. Impatient interdisciplinary rehabilitation after total hip arthroplasty surgery: a comparison of revision and primary total hip arthroplasty. Arch Phys Med Rehabil 2001; 82 (1): 129-33.

13. Ericksson B, Perkins M. Interdisciplinary team approach in the rehabilitation of hip and knee arthroplasties. Am J Occup Ther 1994; 48 (5): 439-45. 